\title{
Coevolution of Cronartium with its Hosts
}

D etlev R. Vogler

Additional indeX WORds. white pine blister rust, pines, currants, gooseberries, Pinus, R ibes

$\mathrm{T}$

raditional views of fungal evolution have proposed that rust fungi of

Pinaceae are among the most ancient of the $U$ redinales, primarily because of the phylogenetic age of their hosts. Recent results from cladistic analyses of morphological and molecular characters have challenged this assumption. O ngoing molecular studies on the phylogeny of the pine stem rust fungi (Cronartium Fries and Peridermium Link) (Vogler and Bruns, 1998) and of their Pinus L. hosts (Liston et al., 1999) provide an opportunity to test coevolutionary hypotheses among these genera. Individual pine stem rust species form clades by telial host family, but without regard to the phylogenetic relatedness of their aecial hosts. Additionally, an evolutionary trend toward greater specialization among telial hosts is evident. R esults suggest that these fungi have had a longer coevolutionary relationship with Angiosperm than Gymnosperm hosts. M ost research on this group has been pursued from the forestry perspective, focusing on genetic interactions of these fungi with aecial hosts (Pinussp.), while ignoring associations with telial hosts (Angiosperms), which have generally been of minor economic importance. Two recent trends in N orth America, an ecosystem management approach to forestry, and burgeoning interest in cultivating new fruit crops for a restless and growing population, have obliged us to look more closely at the biology of both plant hosts and of the fungi that infect them. These trends are especially relevant to the $C$. ribicola J. C. Fischer / white pine/ $R$ ibes L. host-pathogen association. The inadvertently introduced fungus unites these disparate plant species in a biological relationship that has near-term economic and long-term ecosystem consequences that cannot be ignored.

\section{Literature cited}

Vogler, D.R. and T.D. Bruns. 1998. Phylogenetic relationships among the pinestem rust fungi (Cronartium and Peridermium spp.). M ycologia 90:244-257.

Liston, A., W.A. Robinson, D. Pinero, and E.R. Alvarez-Buyalla. 1999. Phylogenetics of Pinus (Pinacea) based on nuclear ribosomal DNA internal transcribed spacer region sequences. M ol. Phylogenet. Evol. 11:95-109. 